\section{and Transportation, Warehousing and July 2019 Utilities Program}

\section{What are our priorities?}

The National Institute for Occupational Safety and Health (NIOSH) Transportation, Warehousing and Utilities (TWU) Program works with partners in industry, labor, government agencies, trade associations, professional organizations, and academia. The program focuses on these areas:

- Reducing transportation incidents and related injuries among TWU workers

- Addressing human-machine interaction to reduce injuries and illnesses among TWU workers

- Reducing work-related obesity and chronic disease among TWU workers.

\section{What do we do?}

- Use surveillance data to guide research and prevention efforts in the TWU sector.

- Research and promote healthy behaviors and work organization factors to reduce fatigue, obesity, and chronic disease.

- Conduct research and provide recommendations to manufacturers,

\section{What have we accomplished?}

- Published a research article on injuries in the Alaskan aviation industry between 2000 and 2013. Leading causes of injuries were falls and crashes.

- Published a research article on the prevalence of musculoskeletal injuries among long haul truck drivers. The most reported injuries were to the arm and back.

- A NIOSH-funded researcher published a research article focused on injuries and illnesses among seafarers (workers on ships and boats that travel the oceans and other waterways). Illnesses were more common than injuries. employers and others to reduce transportation and machine-related injuries.

- Work with partners and the National Occupational Research Agenda (NORA) TWU Sector Council to widely disseminate research findings and prevention recommendations.

\section{At-A-Glance}

The Transportation, Warehousing and Utilities (TWU) Program provides leadership to eliminate occupational injuries, illnesses and fatalities among the nearly 7 million workers in these industries. This snapshot shows recent accomplishments and upcoming work.

Traumatic injury fatality rate, per 100,000 fulltime equivalents (FTE) workers

$\rightarrow$ Transportatation and Warehousing $\rightarrow$ Utilities

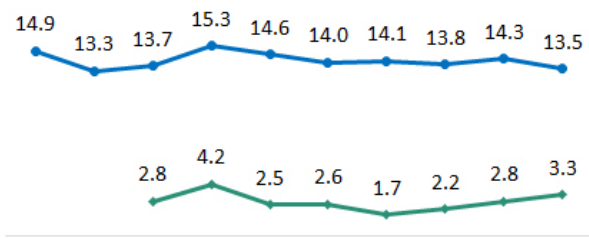

2008200920102011201220132014201520162017

Source: U.S. Bureau of Labor Statistics. Note: Utilities data not reported 2008-2009

The expected progress of vehicle automation (will impact transportation incidents \& related injuries) for improvement in healthy living options for truck drivers at truck stops throughout the U.S.

- Completed a feasibility study requested by the Federal Motor Carrier Safety Administration and recommended methods for conducting a longitudinal study of truck driver health.

- The NIOSH-funded Washington State Fatality Assessment and Control Evaluation (FACE) program published a report on a warehouse worker fatally injured by a driverless forklift and

\title{
What's next?
}

- Publish a research article describing nonfatal work injuries in the Alaskan aviation industry using workers' compensation claims data.

- Provide technical expertise to a study led by the Department of Transportation, in coordination with the Department of Health and Human Services, on the impact of automated vehicles on the workforce. made recommendations for preventing similar deaths with this new type of equipment.
- Publish a NIOSH Science Blog identifying effective components of safety management systems for transportation.

- Participate in a forum on fatigue research needs and gaps, including fatigue among TWU workers.
Percent of workers reporting chronic conditions, 19 states

\section{- TWU ALL}

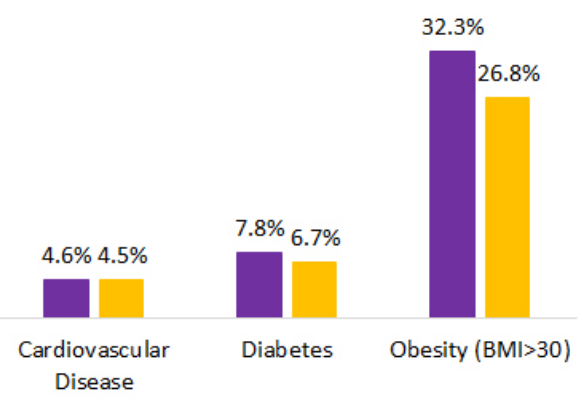

Source: 2013-2015 Behavioral Risk Factor Surveillance System

Note: $\mathrm{BMI}=$ body mass index

To learn more, visit

www.cdc.gov/niosh/programs/twu/ default.html/

Mention of any company or product does not constitute endorsement by the National Institute for Occupational Safety and Health, Centers for Disease Control and Prevention. 